\title{
GFOREETI
}

Forseti. Revista de Derecho. Volumen 10, No 14, Lima, 2021, pp. 30 - 44

\section{La tutela procesal penal de altos dignatarios por la comisión de delitos comunes: De la inmunidad parlamentaria al fuero privilegiado}

\author{
Daniel O. Huamán Castellares*
}

\begin{abstract}
Resumen. - El presente artículo analiza la legitimidad de las prerrogativas procesalespenales de los altos dignatarios del estado peruano para determinar la pertinencia de una reforma en dicho ámbito. De forma particular, se desarolla el concepto de inmunidad parlamentaria, junto a su reciente sustitución por el sistema de fuero privilegiado.
\end{abstract}

\begin{abstract}
The following paper analyzes the legitimacy of the procedural-criminal prerogatives of peruvian high dignitaries to determine the relevance of a reform in this area. In particular, it develops the concept of parliamentary immunity, together with its recent replacement by the system of privileged immunity.
\end{abstract}

Palabras claves. - Tutela Procesal Penal - Derechos Fundamentales - Altos Dignatarios - Inmunidad Parlamentaria - Reforma Constitucional.

Keywords. - Criminal Procedural Protection - Fundamental Rights - High Dignataries - Parliamentary Immunity - Constitutional Reform. 



\section{Preliminares}

Hemos iniciado el bicentenario de nuestro país con la supresión de una histórica prerrogativa procesal-penal (la inmunidad parlamentaria), a la cual seguramente le seguirá la supresión o al menos la modificación de las otras restantes (el antejuicio político y la inmunidad especial del presidente de la República).

El 05 de febrero de 2021 se publicó la Ley 31118, que modificó el artículo 93 de la Constitución Política del Estado. La reforma constitucional en mención alteró significativamente el status quo de las prerrogativas procesales-penales de los altos dignatarios ${ }^{1}$. En dicha reforma se eliminó la impopular, pero ciertamente histórica $^{2}$, garantía constitucional: una inmunidad parlamentaria. En consecuencia, el Congreso de la República eliminó las existentes barreras para el arresto y procesamiento directo que beneficiaban a los parlamentarios y otros altos dignatarios, cambiando la figura hacia un fuero privilegiado ${ }^{3}$.

La percepción sobre la inmunidad parlamentaria no era positiva. Si bien dicha institución tenía la loable finalidad histórica de evitar la persecución de los representantes del pueblo, su uso -al menos en nuestro Congreso de la Repúblicadistaba mucho de dicha finalidad. Aprovechando la imposibilidad de procesamiento directo, un grupo de congresistas se valió de esta garantía para evitar la ejecución de las sentencias penales y su arresto directo ${ }^{4}$ Ergo, en la

1 Texto de la reforma introducido por la Ley 31118: “Artículo 93.- Los congresistas representan a la Nación. No están sujetos a mandato imperativo ni a interpelación.

No son responsables ante autoridad ni órgano jurisdiccional alguno por las opiniones y votos que emiten en el ejercicio de sus funciones. Los magistrados del Tribunal Constitucional y el Defensor del Pueblo gozan de las mismas prerrogativas que los congresistas.

El procesamiento por la comisión de delitos comunes imputados a congresistas de la República durante el ejercicio de su mandato es de competencia de la Corte Suprema de Justicia.

En caso de comisión de delitos antes de asumir el mandato, es competente el juez penal ordinario". (Resaltado nuestro)

2 Para una excelente revisión histórica puede verse: ZAGREBELSKY, Gustavo, Le immunitá parlamentari. Natura e limiti di una garanzia constituzionale, Giulio Eiunadi, Torino 1979, passim.

3 Hace 10 años ya nos adelantábamos a este escenario y pronosticamos la desaparición de la inmunidad y su tránsito hacia un sistema de fuero privilegiado, pues la tendencia es a reducir las prerrogativas y no a maximizarlas. Véase: CARO JOHN, José Antonio y HUAMÁN CASTELLARES, Daniel Osarim, "Notas sobre el procesamiento penal de altos dignatarios por la comisión de delitos comunes. Pasado, presente y futuro de la inmunidad". En: Derecho y Sociedad, $\mathrm{N}^{\circ}$ 34, Derecho y Sociedad, Lima, p. 34.

4 Vid. ROSALES ZAVALA, Leonardo, La inmunidad parlamentaria como mecanismo de impunidad y riesgo de corrupción en el congreso peruano. En: https://core.ac.uk/download/pdf/196533983.pdf, p. 19 - 22; MONTOYA CHÁVEZ, Víctor Hugo, La infracción constitucional, Palestra, Lima, 2005, p. 619. Incluso el propio Tribunal Constitucional ha ido en esa línea interpretativa en contra de esta institución al señalar que: "La prerrogativa de la inmunidad está en franca obsolescencia. Cada vez con mayor fuerza se impone la idea de que es una institución que no cumple con los fines señalados, sino que es escudo de la impunidad. De ahí que sea imperativo una interpretación de sus alcances frente a la necesidad de legitimarla ante la opinión pública. Pero también para devolverle al Ministerio Público y al Poder Judicial su cabal participación en el juzgamiento de los alto funcionarios, entendidos como órganos autónomos e independientes y no como simples mesas de parte" de la voluntad del Congreso" (STC. Exp. N 00156-2012$\mathrm{PHC} / \mathrm{TC}$, caso César Humberto Tineo Cabrera, fundamento jurídico $\mathrm{N}^{\circ} 39$ ) 
práctica, se había creado un incentivo perverso: acceder a una curul en el congreso, para alcanzar la impunidad al menos por un lapso de 5 años.

Si bien la atención de la reforma constitucional se centró en la inmunidad parlamentaria, la mirada pública no fue enfocada por el promotor de la reforma política, el ex Presidente Martín Vizcarra Cornejo, en otro gran sector no abordado de las prerrogativas procesales- penales: el antejuicio político y la inmunidad especial del Presidente de la República.

La presente reforma tuvo como objetivo el reducir los espacios de impunidad. En consecuencia, fue el espacio perfecto para que otros espacios de impunidad generados por las prerrogativas procesales penales de los altos dignatarios fueran discutidos. Gráficamente: si se desea procesar a un alto dignatario por un delito en el ejercicio de sus funciones, los hechos a investigar son fijados por el Congreso de la República, lo que impide al Ministerio Público tener la libertad para agregar otros hechos que pudieran surgir sin previa autorización del Poder Legislativo5; o, incluso frente a casos claros y flagrantes de corrupción. De igual manera, Actualmente no es posible procesar al Presidente de la República, cómo sí es posible en otros países de la región (Bolivia, Brasil, Colombia, Ecuador, entre otros) en la medida que tiene una inmunidad especial que impide ser acusado por actos de función e incluso por delitos comunes durante el ejercicio de su cargo ${ }^{6}$. En todos los casos antes mencionados, resulta clara la existencia de espacios de impunidad generados por las prerrogativas procesales-penales en mención. De ahí que, al igual que la inmunidad parlamentaria, tanto el antejuicio político, como la inmunidad especial del Presidente de la República, deben ser analizados y discutirse su legitimidad, a efectos de determinar si deben o no seguir en vigor en nuestro sistema jurídico.

En la presente contribución analizaremos la legitimidad de las prerrogativas procesales- penales de los altos dignatarios en el contexto actual, para verificar si se justifica o no su existencia o, por el contrario, se requiere una reformarlas. Luego de este análisis abstracto, nos avocaremos al estudio concreto de una de ellas: la inmunidad y su reciente sustitución por el sistema de fuero privilegiado, poniendo un especial énfasis en las necesidades normativas que es necesario prever para que la norma pueda ser aplicada.

5 El presente problema del antejuicio político incluso fue advertido por el Tribunal Constitucional, el cual hace 16 años en la STC. Exp. 00006-2003-AI/TC, fundamento jurídico 17. Fue el propio máximo intérprete de la Constitución quien pide una reforma a la Constitución, pues ella -en los términos actuales- afecta la independencia y autonomía del Poder Judicial y del Ministerio Público. Desde nuestra modesta opinión, el antejuicio político también debe ser suprimido, debiendo ser reemplazado por el sistema de fuero privilegiado. Los mismos fundamentos que desarrollamos en el presente aporte a favor del fuero privilegiado, son los mismos que son aplicables al antejuicio: si se tiene un Poder Judicial y un Ministerio Público autónomos, no resulta necesaria la existencia de un mecanismo de protección frente a actuaciones de corte político. La independencia de ambas instituciones es la mejor garantía que puede tener un alto dignatario.

6 En la misma línea de ampliar los supuestos en los cuales puede acusarse al Presidente de la República: EGUIGUREN PRAELI, Francisco, La responsabilidad del Presidente. Razones para una reforma constitucional, PUCP, Lima, 2007, p. 258. Desde nuestra perspectiva, al igual que en el antejuicio y la suprimida inmunidad parlamentaria, es la independencia de las instituciones del sistema procesal penal la que garantiza un juicio justo a favor del alto dignatario. 
Desde ya anunciamos que consideramos legítimo que se dé un trato diferenciado a favor de los altos dignatarios; sin embargo, no en los términos anteriores, al dejar en manos de un órgano político una decisión exclusivamente jurídica (el arresto y procesamiento de un alto dignatario). Por ello, consideramos apropiado el actual sistema de fuero privilegiado, el cual permite al Ministerio Público y Poder Judicial dilucidar la situación jurídica-penal del alto dignatario sin una autorización previa; y que, al tratarse de los más altos órganos de persecución penal y administración de justicia quienes se encargarían de él, se garantiza un proceso penal con mayores garantías al existir menos presiones sobre Jueces y Fiscales Supremos.

\section{Las prerrogativas constitucionales y el principio de igualdad ante la ley}

Uno de los principios legitimadores de nuestro sistema jurídico es el principio de igualdad ante la Ley. Conforme lo dispone el art. 2, numeral 2, de la Carta Magna, "Toda persona tiene derecho a la igualdad ante la Ley". En virtud de dicho principio, todos los ciudadanos tenemos el derecho a que la norma no haga distingos entre nosotros, salvo que exista una razón que justifique un trato diferenciado. De no ser el caso, y darse un trato distinto sin que medie una razón válida de diferenciación, conforme claramente lo establece la jurisprudencia del Tribunal Constitucional7, estaríamos frente a un supuesto de discriminación.

La igualdad ante la Ley se extiende al plano procesal incluso. Consecuentemente, la norma no puede hacer distinciones entre los ciudadanos, salvo que exista una razón justificada. Una rápida revisión a las normas procesales de nuestro ordenamiento jurídico nos demuestra que existen supuestos en los cuales se da un trato diferenciado, tales como los procesos constitucionales. Dada la urgencia en la tutela y la especial importancia de los derechos fundamentales, la tramitación de un proceso constitucional puede ser realizada con especial premura ${ }^{8}$ y se pueden -tal como sucede en el hábeas corpus- prescindir de ciertas formalidades que no podrían dejarse de lado en los procesos ordinarios (Vgr. La innecesariedad de la firma de abogado en un proceso de hábeas corpus o la posibilidad de plantear este recurso directamente a un juzgado, sin necesidad de respetar el sistema de turnos).

El proceso penal no es la excepción a esta regla y permite excepciones al principio de igualdad ante la Ley, para los funcionarios públicos. Por un lado, el Código procesal penal de 2004 desarrolla el mandato constitucional de procesamiento especial para altos dignatarios ${ }^{9}$ derivados del antejuicio político (arts. 449-451) y de la extinta inmunidad parlamentaria (arts. 452-453). Por otro lado, prevé el procesamiento especial sui generis de otro grupo de funcionarios públicos (Jueces y Fiscales superiores, miembros del Consejo Supremo de Justicia Militar, el

Claramente: STC. Exp. 018-2003-AI/TC.

8 Gráficamente: Cairo Roldán, Omar, “La tutela de urgencia y el proceso de amparo". En: Themis, $\mathrm{N}^{\circ}$ 43, Themis, Lima, 2001, pp. 131-133.

9 Vid. SAN MARTIN CASTRO, César, Derecho procesal penal. Lecciones, $2^{\mathrm{a}}$ ed., INPECCP, Lima, 2020, pp. $1180-1188$. 
Procurador Público, y Jueces y Fiscales de todo el Perú), por delitos cometidos en el ejercicio de sus funciones. En ambos casos se sigue una constante: existen reglas de procesamiento que son aplicables a todos los ciudadanos, pero estas no son aplicables -en razón de su investidura- a estos funcionarios, dándoles ciertas prerrogativas. En la presente investigación sólo se hará referencia al primer grupo, esto es, al análisis de la legitimidad de un sistema de reglas diferenciadas a favor de los altos dignatarios.

La base legal de las prerrogativas procesales-penales de los altos dignatarios es la propia Constitución Política del Perú. Para aquellos delitos en los que no existe una relación directa con el cargo del alto dignatario, pero su función resulta de especial importancia para la nación, ha optado recientemente por aplicar el sistema de fuero privilegiado. Cuando se pretenda el procesamiento penal de un alto dignatario por un hecho que haya sido cometido ejerciendo la función pública a él encomendada, entonces se aplicará el procedimiento del antejuicio político. Finalmente, una última prerrogativa procesal- penal es la que favorece al Presidente de la República, a la que hemos denominado inmunidad presidencial, en virtud de la cual el Presidente de la República no puede ser acusado por ningún delito durante el lapso que ejerza este cargo, salvo puntuales excepciones 10 ; y, en razón del tipo de delito, hasta por cinco años después de que culminara el mandato presidencial. Un mayor detalle puede encontrarse en el presente gráfico:

Prerrogativa procesales-penales de los altos dignatarios en función al cargo y tipo de delito

\begin{tabular}{|l|c|c|c|}
\hline $\begin{array}{l}\text { Funcionario/Tipo } \\
\text { de delito }\end{array}$ & $\begin{array}{c}\text { Fuero } \\
\text { privilegiado } \\
\text { (delito común) }\end{array}$ & $\begin{array}{c}\text { Antejuicio Político } \\
\text { (delito en ejercicio } \\
\text { de la función) }\end{array}$ & $\begin{array}{c}\text { Inmunidad } \\
\text { presidencial }\end{array}$ \\
\hline $\begin{array}{l}\text { Presidente de la } \\
\text { República }\end{array}$ & $\mathrm{X}$ & $\mathrm{X}$ \\
\hline Congresista & $\mathrm{X}$ & $\mathrm{X}$ & \\
\hline $\begin{array}{l}\text { Juez del Tribunal deje el } \\
\text { Constitucional }\end{array}$ & $\mathrm{X}$ & $\mathrm{X}$ & \\
\hline $\begin{array}{l}\text { Defensor del } \\
\text { Pueblo }\end{array}$ & $\mathrm{X}$ & $\mathrm{X}$ & \\
\hline
\end{tabular}

10 Este punto es especialmente interesante, pues el art. 117 de la Constitución Política del Perú sólo impide la acusación, mas no dice absolutamente nada de la investigación del Presidente de la República por un hecho acaecido durante su mandato. Sobre el punto existen dos interpretaciones posibles: que la investigación espere a que el Presidente termine su mandato o que la investigación continúe pero sólo a nivel preliminar. Desde nuestra perspectiva es la segunda alternativa resulta acorde con el deseo de reducir las brechas de impunidad, pues permite al Ministerio Público realizar actos de indagación de forma pronta y no esperar hasta la culminación del periodo presidencial. 


\begin{tabular}{|l|c|c|}
\hline $\begin{array}{l}\text { Jueces de la Corte } \\
\text { Suprema }\end{array}$ & $\mathrm{X}$ & \\
\hline $\begin{array}{l}\text { Fiscales } \\
\text { Supremos }\end{array}$ & $\mathrm{X}$ & \\
\hline $\begin{array}{l}\text { Ministros de } \\
\text { Estado }\end{array}$ & $\mathrm{X}$ & \\
\hline $\begin{array}{l}\text { Miembros de la } \\
\text { Junta Nacional de } \\
\text { Justicia }\end{array}$ & $\mathrm{X}$ & \\
\hline $\begin{array}{l}\text { Contralor } \\
\text { General }\end{array}$ & $\mathrm{X}$ & \\
\hline
\end{tabular}

Elaboración: Propia

La legitimidad de las prerrogativas procesales-penales, a entender de los pronunciamientos del Tribunal Constitucional, reposaría en la necesidad de reforzar las instituciones a las que representan los funcionarios públicos que detentan estas prerrogativas ${ }^{11}$. Así, por ejemplo, en el caso de la sustituida inmunidad parlamentaria se procuraba que el parlamento pueda desempeñar mejor sus funciones, sin el riesgo de que sus miembros sean sometidos a una persecución política. De la misma manera, el antejuicio protege a los altos dignatarios y se aduce que evitaría su persecución política, delegando al Congreso de la República la labor de filtrar las denuncias contra ellos. Por último, dada la alta responsabilidad que implica el ejercicio de la Presidencia de la República, se habría optado por impedir su procesamiento mientras él ejerza el cargo, a efectos de que pueda concentrarse en su alta función.

En síntesis, las prerrogativas procesales-penales son una clara afectación del mandato de igualdad ante la Ley. Sin embargo, al existir una finalidad mayor que justifica el trato diferenciado, son afectaciones válidas a dicho principio.

\section{Del sistema de inmunidad parlamentaria al sistema del fuero privilegiado}

La tutela jurídico procesal penal de los altos dignatarios se basaba en el sistema de inmunidad parlamentaria. Por ende, si se quería arrestar, procesar o ejecutar la pena contra un alto dignatario por delitos comunes cometidos antes y durante el ejercicio de su cargo, debía ser solicitada la autorización a sus pares: los otros Congresistas de la República, quienes determinaban si en la causa existía o no una finalidad política.

En la actualidad, la tutela jurídica procesal penal se fundamenta en el sistema de

11 STC. Exp. 00026-2006-AI/TC; STC. Exp. 00013-2009-AI/TC, fundamento jurídico № 29. 
fuero privilegiado. Se denomina así porque no es un órgano común el que se encarga del procesamiento penal del alto dignatario, sino es el máximo órgano del sistema de justicia penal: la Corte Suprema de la República, quien se avoca al conocimiento de la causa instaurada contra el alto dignatario, por la atribuida comisión de delitos sin ejercer la función pública durante el tiempo que ejerce la función pública. Asimismo, en este sistema, a diferencia de lo que sucede en el antejuicio político (diseñado para casos donde se impute al alto dignatario la comisión de un delito valiéndose de la función pública que detenta), no se requiere de una autorización previa del Congreso de la República, ni tampoco la imputación se encuentra delimitada por la institución en mención. En su lugar, la imputación formulada por el Ministerio Público va directamente al Juez penal encargado de la Corte Suprema.

En este nuevo sistema, la determinación de si la causa penal tiene o no una motivación política queda en mano de los operadores del sistema de justicia penal y no del Congreso de la República. Así, el Ministerio Público determina los hechos a imputar y propone su calificación jurídica de forma autónoma. De igual manera, la Corte Suprema de la República tiene plena autonomía para decidir si los hechos imputados pueden o no ser subsumidos en un tipo penal. En buena cuenta, se suprime el filtro político, porque se cree en la independencia de las autoridades encargadas de la investigación del delito y de su juzgamiento.

\section{i. ¿Resulta legítimo el cambio de sistema?}

En la actualidad no podemos hablar de una modificación o reducción de la inmunidad parlamentaria. Somos categóricos al afirmar que tal inmunidad ya fue eliminada de nuestro sistema jurídico, siendo sustituida por el sistema de fuero privilegiado.

Sustentamos nuestra opinión en la supresión del contenido esencial que históricamente ha definido a la inmunidad parlamentaria, nos referimos al impedimento de arresto y procesamiento de un parlamentario sin la previa autorización de sus pares. En su lugar, lo que se ha establecido -a semejanza de lo previsto en la Constitución Política de Colombia- es un sistema de fuero privilegiado. Ergo, desde el 05 de febrero de 2021, ni el procesamiento, ni el arresto de Congresistas de la República, miembros del Tribunal Constitucional y el Defensor del Pueblo, por delitos comunes cometidos durante el ejercicio de sus funciones, requieren de autorización previa. La competencia para el procesamiento de estas causas ahora pertenece a la Corte Suprema de la República.

La razón de ser de la inmunidad, como prerrogativa procesal-penal, tiene su origen en la institución propia del Derecho ingles denominada freedom of arrest ${ }^{12}$. En virtud de dicha institución no podía impedirse a un parlamentario acudir a su correspondiente cámara, cuando la causa del arresto tuviera su origen en una

12 Cfr. MAY, Thomas Erskine, Erskine May's Treatise on the law, privilegies, proceedings and usage of Parliement, 21a ed., Buterworths, London 1989, p. 74 y ss. 
razón civil (fundamentalmente deudas) ${ }^{13}$. Para evitar dicha obstrucción, la Cámara de los Comunes decretó la imposibilidad de arrestar a sus integrantes, mientras ellos se encontraran en el ejercicio de su cargo.

Sobre la base del freedom of arrest, en la Francia revolucionaria se definieron los contornos concretos de lo que actualmente conocemos como inmunidad parlamentaria. Dadas las manifiestas tensiones entre el Rey y los asambleístas, existía un fundado temo de los últimos de ser objeto de una persecución jurídicapenal basada en motivos políticos, si es que sus decisiones contradecían los deseos del Rey.

El origen de este temor era real, pues el equilibrio de poderes en dicho momento era sólo una aspiración. Por el contrario, el Rey tenía injerencia sobre la persecución y procesamiento penal de todo ciudadano, incluso de los propios asambleístas. De ahí que, para que no se interrumpieran las funciones de la Asamblea Nacional francesa, se prohibiera el arresto y persecución de los asambleístas, sin una aprobación previa de sus pares ${ }^{14}$.

Tal como podemos ver, en atención a su origen histórico, la razón de ser de la existencia de la inmunidad parlamentaria fue evitar la persecución política en contra de los representantes directos del pueblo: los congresistas. Específicamente, se deseaba evitar el arresto de los parlamentarios por razones políticas. Para que esta premisa pudiera seguir teniendo vigor, entonces debería aseverarse la existencia probable de una influencia del Poder Ejecutivo, $\mathrm{u}$ de otro sector, sobre el Poder Judicial y el Ministerio Público, los cuales permitieran afirmar que el Poder Ejecutivo pudiera influir en las dos instituciones encargadas de la investigación y juzgamiento penal, lo suficiente como para que se pueda arrestar o procesar por razones políticas al alto dignatario.

Ergo, aceptar la existencia de la inmunidad implica aceptar la falta de independencia del Poder Judicial y del Ministerio Público, a quienes - implícita e indebidamente- se les quitaría la confianza como órganos capaces de dilucidar si existe o no una persecución política en contra del alto dignatario. De ahí que, para garantizar la seguridad de los parlamentarios y en atención a la alta función que realizan, sólo ellos podrían decidir si existe o no un motivo político detrás de las causas jurídicas-penales instauradas en su contra.

En nuestro país el arresto de una persona, sea quien ella fuere, sólo puede ser posible en dos supuestos: como consecuencia de la existencia de flagrancia delictiva o por una decisión judicial, la que -a su vez y en su mayoría- se origina por la imposición de medida cautelar, la comparecencia compulsiva y la ejecución de una sentencia condenatoria.

13 La protección inicial no impedía la protección por hechos derivados de causas penales, sino civiles estrictamente. Vid.. MAY, Erskine May's Treatise on the law, privilegies, proceedings and usage of Parliement, cit., p. 74.

14 Para un mayor desarrollo de cómo se produjo este proceso de adaptación de las garantías inglesas al sistema jurídico francés, puede verse: ZAGREBELSKY, Le immunitá parlamentari. Natura e limiti di una garanzia constituzionale, cit., pp. 1 - 20. 
El Poder Ejecutivo sólo podría tener algún tipo de injerencia directa sobre el primer supuesto, el arresto en flagrancia, porque orgánicamente la Policía Nacional del Perú depende de él. No obstante, la Policía Nacional del Perú, jurídicamente, se encuentra sujeta directamente a la Constitución y la Ley. Por ende, la existencia de un supuesto de detención en flagrancia que no cumpla los requisitos legalmente exigidos para ello (inmediatez temporal y personal), sería muy difícil de darse en la práctica. Asimismo, dicha detención debe ser convalidada por un órgano que se encuentra por encima de la Policía Nacional del Perú en la persecución del delito: el Ministerio Público. Ergo, así estuviéramos en el supuesto muy difícil de que la detención de un alto dignatario sea el producto de un acto de persecución política y no de un real caso de flagrancia, la legalidad de la detención será controlada en primer lugar por el Ministerio Público, a quién se le asigna un plazo máximo de detención (48 horas por regla general y excepcionalmente -terrorismo, tráfico de drogas y organización criminal- por 15 días naturales). $\mathrm{Y}$, posteriormente, será un Juez, previo pedido del Ministerio Público, quién decida si impone o no una medida cautelar en contra del detenido.

Si lo que se requiere es una medida cautelar que habilite el arresto como la detención preliminar o la prisión preventiva, el primer filtro es el Ministerio Público, pues el Código procesal penal establece claramente que sólo él tiene la legitimidad para solicitar este tipo de medidas cautelares personales ${ }^{15}$. Consecuentemente, otros sujetos procesales que dependen del Ejecutivo funcionalmente, como la Policía Nacional del Perú o la Procuraduría Pública, tampoco tienen la posibilidad de incoar la detención preliminar o la prisión preventiva ante un Juez penal.

De otro lado, la actuación del Ministerio Público es meramente postulatoria ${ }^{16}$. Ergo, él no adopta una decisión que limite de forma grave la libertad personal de un alto dignatario. Para que una medida cautelar sea impuesta o para que se emita una sentencia condenatoria, nuestro sistema jurídico procesal penal exige que sea un Juez quién decida si, en el caso concreto, se dan los supuestos legalmente exigidos para imponer una medida cautelar o para condenar a una persona ${ }^{17}$.

El Juez es el más importante garante de los derechos fundamentales del imputado y la sociedad al interior de un proceso penal. Nuestra Constitución lo ha dotado de la potestad de administrar justicia, por lo que es quien finalmente concreta la

15 La razón de ello es que, en el nuevo modelo procesal penal, al ser el Ministerio Público el titular de la acción penal, sólo él tiene legitimidad para solicitar medidas cautelares que tengan relación con las consecuencias jurídico-penales. Cfr. SÁNCHEZ VELARDE, Pablo, “La prisión preventiva en el Código procesal penal de 2004". En: HURTADO POZO, José (Dir.), Anuario de Derecho penal, Universidad de Friburgo-PUCP, Lima, 2009, pp. 103 $-104$.

16 De esta postura es el Tribunal Constitucional, el cual se ha pronunciado sobre ello en: STC. Exp. $\mathrm{N}^{\circ}$ 00680- 2019-PA/TC, fundamento jurídico 6, con referencias al STc. Exp. $\mathrm{N}^{\circ}$ 02430-2013PHC/TC, fundamento jurídico 4.

17 La prisión preventiva implica una grave afectación al derecho fundamental a la libertad personal. Por ello, la legitimidad de su imposición reposa en requisitos de fondo, como son los presupuestos procesales por los que es otorgada, así como en la legitimidad del órgano encargado de impartirla. Sólo el Poder Judicial, que se encuentra ajeno a las partes, tiene la capacidad de limitar este derecho fundamental. 
abstracción de la norma en una decisión que surtirá un efecto sobre una persona concreta. En consecuencia, su decisión no se ampara en lo que es políticamente conveniente, sino en lo que la legalidad vigente (entendida no sólo como Ley, sino también abarcando a la Constitución y Tratados de Derechos Humanos) determina.

Si estuviéramos en la Francia del siglo XVIII, en la cual el nombramiento de un Fiscal o de un Juez era realizado por el propio monarca, sí se justificaría un temor fundado a una injerencia posible del Rey en contra de aquella persona que -como los parlamentarios- podría resultarle incómoda. Consecuentemente, sí sería posible constatar un riesgo de injerencia política en un acto procesal penal. No obstante, la situación del Perú actual dista mucho de la situación antes descrita.

En el Perú, el nombramiento de Jueces y Fiscales no emana del Poder Ejecutivo. En la Constitución Política del Perú se ha creado un órgano independiente, recientemente reconfigurado para encargarse de dicha función: la Junta Nacional de Justicia. La razón de su existencia es precisamente despolitizar el nombramiento de tan importantes funcionarios. De esa forma, al tener independencia con respecto al Poder Ejecutivo y al Poder Legislativo, los Jueces y Fiscales son autónomos en las decisiones que tomen contra los miembros de ambos poderes, lo que contribuye a debilitar la hipótesis de la persecución política.

En esa línea argumentativa, si la decisión de privar de la libertad personal a un ciudadano depende de dos instituciones cuya independencia se encuentra constitucionalmente garantizada, entonces se reduce sensiblemente el riesgo de que el Poder ejecutivo, $u$ otro sector, pueda influir en la decisión que tomen un Fiscal o un Juez de privar de la libertad a un alto dignatario. De ahí que, evidenciamos la gran diferencia contextual entre la situación de un asambleísta francés en el seno de un Estado absolutista, con el riesgo real que corre un alto dignatario (congresista, defensor del pueblo o magistrado del Tribunal Constitucional) en la actualidad. Coherentemente, el riesgo se ha reducido muy sensiblemente, lo que hace legítima la supresión del impedimento de arresto directo y procesamiento a favor del alto dignatario.

Finalmente, con respecto al fuero privilegiado, es necesario precisar que su legitimidad reposa en la idea de que el más alto órgano de administración de justicia puede brindar una mayor garantía de impedir que la persecución se fundamente en razones políticas.

En la medida que el desempeño de la alta función pública todavía debe ser protegido, es que el legislador optó por la sustitución de la prerrogativa procesal y no por su supresión. No obstante, tal como va evolucionando el sistema jurídico constitucional y su deseo de limitar los potenciales espacios de impunidad o suprimir prerrogativas procesales-penales otorgadas a altos dignatarios, es posible que -en un futuro no muy lejano- incluso la garantía de fuero privilegiado sea eliminada, dando pase a un juzgamiento penal por los tribunales ordinarios de ciertos altos dignatarios por la comisión de delitos sin ejercer la función pública. 


\section{ii. Tarea pendiente: la modificación del Código procesal penal para preveer el sistema de fuero privilegiado}

El actual sistema de fuero privilegiado ya no requiere de un pronunciamiento o autorización previa de parte de los pares del alto dignatario para el arresto o procesamiento. Si bien es un gran avance, todavía se trata de un sistema que establece una prerrogativa procesal-penal: el procesamiento de los hechos imputados a un alto dignatario en funciones a cargo de la Corte Suprema de la República. No obstante, la sustitución a nivel constitucional de la prerrogativa no había ido a la par con las modificaciones necesarias para su operatividad, pues aún existían vacíos en la norma procesal penal para que la reforma tenga una eficacia real y, sobretodo, se pueda superar distintos problemas que en la práctica dificultarían la persecución penal contra un alto dignatario.

El día 24 de julio del presente año se ha publicado la Ley 31308 ha modificado los artículos 450, 453, 453 y 454 del Código procesal penal, modificaciones que analizaremos críticamente a continuación:

\section{La competencia de la Fiscalía}

Tradicionalmente el procesamiento penal de un alto dignatario por la comisión de un delito común, cuando él se encontraba en el ejercicio de sus funciones, seguía las reglas procedimentales aplicables a cualquier otro ciudadano. Por ende, la competencia de la Fiscalía correspondía a un Fiscal provincial penal corporativo, para casos cometidos en distritos judiciales donde se encontraba vigente el Código procesal penal de 2004; y, para aquellos casos donde se encontraba vigente el Código de procedimientos de 1939, la competencia la tenía el Fiscal provincial penal corporativo.

Con la reforma constitucional bajo análisis quedaba un enorme vacío al no determinarse en la propia Constitución Política del Perú cuál era el Fiscal competente para conocer la causa penal, pues la reforma constitucional establece únicamente que el juzgamiento será ante la Corte Suprema, dejando la aparente incógnita sobre el Fiscal Competente para ejercer la acción penal.

En el sistema jurídico colombiano, de donde tiene su origen la actual reforma, este problema no existe, pues la competencia para este tipo de casos se encuentra expresamente designada a los Fiscales Delegados ante la Corte Suprema1818. No obstante, en nuestro país dicha competencia no había sido asignada, conforme se aprecia de una lectura completa de la Ley Orgánica del Ministerio Público o del Código procesal penal antes del 24 de julio de 2021. Tan sólo se encontraba regulada la competencia para casos donde estén involucrados los altos dignatarios con la garantía del antejuicio político, la cual es asignada al Fiscal de la Nación.

18 En virtud del Decreto Ley N 016-2014, artículo 5, numeral 1, la competencia por la investigación y pronunciamiento a favor de funcionarios con fuero constitucional es de competencia de la Fiscalía Delegada ante la Corte Suprema de la República. 
Si se atiende a la finalidad de encargar el juzgamiento de estos casos a la Corte Suprema de la República, entonces la reforma -sea al Código procesal penal o a la Ley Orgánica del Ministerio Público- debía asignar la competencia a un Fiscal Supremo especializado en lo penal, para que se encargue -en primera instanciadel Juzgamiento del alto dignatario. Consideramos este sistema más idóneo que el encargar directamente la investigación y acusación al Fiscal de la Nación, pues así reserva la competencia del Fiscal de la Nación para los recursos como de consulta, para la participación en la apelación y en general para todo acto que requiera un segundo análisis de la causa penal.

Antes del 24 de julio de 2021, si se pretendiera procesar a un alto dignatario aparentemente el ejercicio de la acción penal habría estado reservado al Fiscal de la Nación, conclusión que podría encontrarse en el art. 66, numeral 2, de la Ley Orgánica del Ministerio Público, el cual le otorga la capacidad de actuar ante la Corte Suprema para el procesamiento de casos contra altos dignatarios. No obstante, tal como la propia norma lo establece, se refiere a casos donde el Congreso hubiera aprobado el procesamiento, esto es, para los funcionarios y casos previstos en el art. 99 de la Constitución Política del Perú. Ergo, la competencia del Fiscal de la Nación para el ejercicio de la acción penal ha sido limitada a funcionarios con la prerrogativa procesal-penal del antejuicio político.

Por ello, al no existir una norma especial que designe la competencia de la investigación al Fiscal de la Nación o a un Fiscal Supremo, el fiscal competente para conocer la causa habría sido un Fiscal Provincial penal (casos del Código de procedimientos de 1939) o un Fiscal Provincial Penal Corporativo (Código procesal penal de 2004). Naturalmente, esto podría conllevar muchos problemas de orden logístico, los cuales serían más visibles en casos iniciados contra el congresista fuera de Lima, pues obligaría a que la investigación sea realizada en un distrito judicial distinto al lugar donde el procesamiento será realizado. Salvo que la informática avance lo suficiente y la virtualidad se vuelva la regla en los actuales procesos penales, esta diferencia de lugares conllevaría a problemas en el desplazamiento del Fiscal de origen a la capital cada oportunidad que fuera necesaria su presencia para una posible audiencia de tutela, el control de acusación, el juicio oral, entre otros.

En la actualidad, a raíz de la Ley 31308, la competencia de la Fiscalía queda expresamente designada a favor de un Fiscal supremo, de acuerdo al art. 452, numeral $1{ }^{19}$. Podría existir una polémica en torno a cuál de todas las Fiscalías Supremas sería la competente para analizar la causa. No obstante, resulta meridianamente claro que sólo podrían ser competentes la Primera y la Segunda Fiscalía Supremas, pues ellas se avocan a casos de delitos comunes. Consecuentemente, ellas tendrían competencia para analizar estas causas.

19 “La investigación y juzgamiento, en los supuestos del numeral 1 del artículo anterior, están a cargo de la Fiscalía Suprema y la Corte Suprema de Justicia, respectivamente". 
Un hecho que llama poderosamente la atención es la mala redacción de la Ley 31308, pues el art. 453, numeral $2^{20}$, induce al error de considerar las etapas de investigación preparatoria y de enjuiciamiento se nombrarán a dos fiscales distintos: uno para la etapa de investigación preparatoria y otro para el juzgamiento del alto dignatario. Consideramos esta redacción un error, pues en el actual proceso penal el Fiscal encargado de seguir la investigación preparatoria es el mismo que se encarga de sustentar su acusación en el juicio oral. Consideramos que la razón más importante por la que sólo un fiscal debe encargarse de la investigación y del enjuiciamiento reside en el conocimiento de la causa. Aquel fiscal que se encarga de la investigación preparatoria tiene un amplio conocimiento sobre el caso, sobre los medios de prueba que se actuarán en el juicio oral, sobre los argumentos de las partes, entre otros. De ahí que optar por un nuevo Fiscal que se encargue de esta etapa podría significar en un retroceso para la causa. Si bien el nuevo fiscal podría prepararse y asumir correctamente el nuevo caso en un juicio oral, pero el tiempo que ello demoraría prolongaría la duración del proceso de forma innecesaria.

\section{La competencia en caso de cese de funciones del alto dignatario}

Antes de la reforma constitucional, el procesamiento del alto dignatario al que se levantaba la inmunidad correspondía a un fuero ordinario, siguiendo las reglas previstas en el Código procesal penal de 2004 o del Código de procedimientos penales de 1939. No obstante, la reforma constitucional en comentario cambia radicalmente el supuesto anterior y establece un sistema diferenciado. Para los casos donde la imputación sea el cometer un delito sin ejercicio de la función pública (delitos comunes), los cuales fueran imputados con anterioridad al ejercicio de la función del alto dignatario, la reforma constitucional ha previsto que el procesamiento siga a cargo de un juez penal ordinario. Para los casos en los que la imputación surja cuando el alto dignatario se encuentre en ejercicio del cargo, por hechos sin ejercer la función pública, la competencia del procesamiento la tendrá la Corte Suprema de la República.

Existen distintos problemas prácticos que este doble sistema no ha previsto, como la competencia de un caso tramitado ante la Corte Suprema en contra de un alto dignatario, luego de que él haya dejado el cargo ¿Debería automáticamente volver a ser de competencia de un juez penal ordinario o debería mantenerse en el fuero de la Corte Suprema de la República? Si atendemos al principio de economía procesal, podríamos entender que la competencia por estos delitos correspondería aún a la Corte Suprema de la República, al haber ella adquirido la competencia y para evitar la realización de actos procesales que ya habrían sido realizados.

20 "Ante la disposición de formalización de la investigación preparatoria u otros requerimientos fiscales a nivel de diligencias preliminares, la Sala Penal de la Corte Suprema designará, entre sus miembros, al Juez Supremo de Investigación Preparatoria y a los integrantes de la Sala Penal Especial Suprema, que se encargará del juzgamiento; y, Fiscal de la Nación hará lo propio respecto a los Fiscales Supremos que conocerán de las etapas de investigación preparatoria y de enjuiciamiento." 
El problema es resuelto por el art. 452, numeral 121, del Código procesal penal de 2004, el que opta porque los procesos iniciados en el fuero privilegiado se mantengan, incluso cuando el alto dignatario haya cesado su función. De esa opinión somos al interpretar que la norma en comentario sólo hace referencia a la competencia para el conocimiento de estos casos, sin establecer un límite que restrinja la competencia a un momento determinado.

Otro punto interesante, no resuelto expresamente, es el referido a la situación de una imputación en la cual el alto dignatario se encuentre procesado con personas no aforadas. ¿Debería tener competencia la Corte Suprema para el juzgamiento de todos los imputados o debería partirse la investigación y encargar el juzgamiento de los no aforados al juez penal competente? Desde nuestra perspectiva, nuevamente sobre la base del principio de economía procesal, es preferible tener una sola investigación y no dos en paralelo. De ahí que, el procesamiento de los no aforados debería seguir la suerte del parlamentario, defensor del pueblo o del integrante del Tribunal Constitucional, ergo, todo el caso debería ser analizado en la Corte Suprema de la República.

\section{Conclusiones}

En primer lugar, las prerrogativas procesales-penales de los altos dignatarios significan una afectación al principio de la igualdad ante la Ley, pues implican dar a los altos dignatarios un trato distinto al que reciben el resto de ciudadanos. No obstante, en atención a la importancia de las funciones que ellos realizan, se ha optado por dotarlos de prerrogativas procesales-penales, las que -conforme los tiempos van cambiando y se da mayor independencia del sistema de persecución penal- se encuentran en proceso de reducción.

En segundo lugar, la inmunidad de arresto es históricamente una de las garantías más importantes, cuyas bases históricas se remontan a la Francia revolucionaria de fines del siglo XVIII. La inmunidad era necesaria en un momento histórico en el que el Rey podía ingerir en la persecución penal del asambleísta. Por ello, la Asamblea Nacional decidió la imposibilidad de arresto del asambleísta por causas penales, sin previa aprobación de sus pares.

En un contexto como el actual, en el que la injerencia directa que puede tener el Poder Ejecutivo sobre el Poder Judicial o el Ministerio Público es poca o nula, no se legitimaba la existencia de la inmunidad parlamentaria. Por ello, fue atinada la reforma constitucional de febrero de este año, la cual eliminó el contenido esencial de la inmunidad parlamentaria y la reemplazó por un sistema de fuero privilegiado.

En tercer lugar, luego de la modificatoria del Código procesal penal de 2004, realizada el 24 de julio de 2021, quedan más claros los contornos legales del sistema

21 "El procesamiento por la comisión de delitos comunes imputados a los Congresistas de la República, el Defensor del Pueblo y los miembros del Tribunal Constitucional durante el ejercicio de su mandato es de competencia de la Corte Suprema de Justicia de la República y se rigen por las reglas del proceso común, así como por lo establecido en el presente Título." 
de fuero privilegiado. Aspectos tales como el fiscal competente para la investigación, la competencia para investigaciones en trámite, entre otros supuestos, ahora ya fueron abordados.

Si bien el actual sistema de fuero privilegiado es un interesante avance, el futuro debería avizorar la supresión de las prerrogativas procesales-penales de todos los altos dignatarios, tanto por delitos cometidos en el ejercicio de la función pública o sin él.

Asimismo, esta reforma no sólo debería incluir a la inmunidad parlamentaria y al antejuicio político, sino que debería también ser extensible a la inmunidad presidencial. La reforma constitucional de las prerrogativas procesales-penales no eliminará la corrupción u otro problema endémico de la alta función pública, pero contribuirá sensiblemente a poder combatirla. 